\title{
Sexual Harassment Policies in K-12 Schools: Examining Accessibility to Students and Content
}

LAUREN F. LICHTY, MA

JENNIFER M.C. TORRES, BS ${ }^{b}$

MARIA T. VALENTI, MA

NiCole T. Buchanan, PhD

\begin{abstract}
BACKGROUND: Peer sexual harassment is a significant social problem with consequences for both students and schools. Four out of 5 students report experiencing sexual harassment. These experiences have been linked to poor psychological health and academic withdrawal. Recognizing the seriousness of sexual harassment in schools, Supreme Court rulings have established school liability for known instances of sexual harassment under Title IX of the Education Amendments of 1972. Federal guidelines established by the Office for Civil Rights of the US Department of Education mandate schools to develop sexual harassment policies; however, the implementation of these guidelines has not been examined. Therefore, this study assessed the degree to which sexual harassment policies in primary and secondary schools adhered to said guidelines.
\end{abstract}

METHODS: This study evaluated 784 primary and secondary school sexual harassment policies across 4 states on 3 key factors: accessibility to students (ie, via the Internet), consistency with federal guidelines regarding their content and the inclusion of 10 key components, and consistency of content across educational levels.

RESULTS: Only $14 \%$ of sexual harassment policies were available online; the majority of policies incorporated only 5 of the 10 critical components, and elementary school policies contained significantly fewer components than all other educational levels.

CONCLUSIONS: The Internet is an underused resource for disseminating school sexual harassment policies to students. When policies are available, they rarely incorporate the key elements specified in the federal guidelines. Particularly troubling are the inaccessibility and incompleteness of elementary school policies. Greater attention to policy accessibility and comprehensiveness is needed.

Keywords: policy; legal issues; Title IX; sexual harassment; prevention.

Citation: Lichty LF, Torres JMC, Valenti MT, Buchanan NT. Sexual harassment policies in K-12 schools: examining accessibility to students and content. J Sch Health. 2008; 78: 607-614.

aDoctoral Candidate, (lichtyla@msu.edu), Department of Psychology, 65 Psychology Bldg, Michigan State University, East Lansing, MI 48824-1116.

bDoctoral Candidate, (jennymct@umich.edu), Department of Sociology, 3001 LSA Bldg, University of Michigan, Ann Arbor, Ml 48109-1382.

'Doctoral Candidate, (valent60@msu.edu), Department of Psychology, 65 Psychology Bldg, Michigan State University, East Lansing, Ml 48824-1116.

dAssistant Professor, (nbuchana@msu.edu), Department of Psychology, 105C Psychology Bldg, Michigan State University, East Lansing, MI 48824-1116.

Address correspondence to: Lauren F. Lichty, Doctoral Candidate, (lichtyla@msu.edu), Department of Psychology, 65 Psychology Bldg, Michigan State University, East Lansing, Ml 48824-1116.

Support for this study came from the National Institutes of Health and the Michigan State University Families and Communities Together grant. We are grateful to Brynn Pollick and Dayna Tatebe for their assistance in data collection, Rebecca Campbell for feedback on analyses, and Mindy Bergman for critiquing the manuscript. 
$S_{a}$ chool-based peer sexual harassment emerged as an area of research in the early 1990s, with researchers finding that it is both common and detrimental to youth. School-based sexual harassment is defined by social science researchers as any unwanted sexual behavior that interferes with a student's life $\mathrm{i}^{1,2}$ or educational opportunities. ${ }^{3}$ Two of the largest nationally representative studies of sexual harassment in schools found that approximately 4 out of 5 students in grades 8 through 11 reported experiencing sexual harassment at some time during their school life. ${ }^{1,2}$ Subsequent studies have found equally high prevalence rates, indicating that sexual harassment is pervasive among American youth. ${ }^{4-6}$

Both youth and schools report a number of negative consequences of sexual harassment. Perhaps most important are the psychological and academic consequences for students. Harassed youth report detrimental psychological outcomes such as feeling fearful, upset, ${ }^{1,2}$ worthless, and helpless against the harassment. ${ }^{6,7}$ Victimized students also experience academic consequences: approximately $25 \%$ report talking less in class; $20 \%$ indicate they are having difficulty paying attention at school; and $17 \%$ admit to skipping school, dropping out of activities, or dropping classes as a result of harassment. ${ }^{1,2}$

Not only does sexual harassment harm the student targeted, but it also creates a hostile environment for all students, thereby negatively affecting school climate. Positive, safe school climates have been found to promote better teaching, learning, and psychological processing among both teachers and students. ${ }^{8-10}$ Behaviors that contribute to a negative school climate, such as sexual harassment, are in direct conflict with the primary goals of schools - to teach effectively and to enhance student learning.

Some students have filed formal charges against their schools for failing to intervene and end harassment. Such charges are costly for schools in a number of ways. Publicity resulting from students being harassed is likely to damage the reputation of the school as well as the surrounding community. The financial costs related to sexual harassment are also a concern. Supreme Court cases have established school liability for sexual harassment, allowing damages to be awarded to claimants if the school district showed deliberate indifference to known acts of sexual harassment. Cherner-Ranft and others ${ }^{3,1-14}$ provide reviews of relevant cases. When such cases go to court, schools incur considerable litigation costs, and prevailing plaintiffs have been awarded anywhere from \$15,000 to more than \$400,000. Given the current funding constraints on public education, expenditures related to sexual harassment litigation and settlements could financially devastate a school district.

The primary federal statute that protects students from sexual harassment is Title IX of the Education
Amendments of 1972. Title IX specifically applies to federally funded educational programs and activities and states that no individual shall be subjected to discrimination, excluded from participation in, or denied the benefits of an education on the basis of his or her sex. ${ }^{1,14}$ Court rulings determined that sexual harassment constitutes a form of sex discrimination in that it inhibits full participation in one's education. Therefore, under Title IX, schools that receive federal funds are held accountable for any student's or staff member's behavior that they reasonably could have known occurred and that involves the deliberate harassment of a student in a manner that denies equal access to an educational program or activity. ${ }^{3,15}$ Failure to effectively address sexual harassment can result in civil prosecution by victims as well as administrative consequences such as the loss of federal funding.

In order to ensure that schools are consistently and appropriately attending to sexual harassment as required by law, the Office for Civil Rights (OCR) of the US Department of Education mandated that schools develop sexual harassment policies and procedures. ${ }^{16}$ According to the OCR (2001), to be in compliance with Title IX regulations, educational institutions must publish and disseminate (1) a policy opposing sex discrimination (of which sexual harassment is a form), (2) a grievance procedure for complainants, and (3) procedures for the "prompt and equitable resolution of complaints." Although sex discrimination policies need to pointedly address sexual harassment so that students and staff understand that the policy encompasses sexual harassment, the exact content of the policy is not regulated. However, the OCR set forth guidelines for the construction of effective nondiscrimination policies and procedures that will not only meet Title IX regulations but also be better suited to prevent sexual harassment. ${ }^{16}$ The American Council on Education (ACE) also developed guidelines for sexual harassment policies. ${ }^{17-19}$ Table 1 provides a summary of the OCR and ACE recommendations. The OCR suggests that by having explicit policy statements and "accessible, effective, and fairly applied" grievance procedures, schools are simultaneously communicating intolerance for sexual harassment and assuring targets that they are safe in reporting sexually harassing behaviors. If policies are adopted and implemented effectively, sexual harassment should decrease, resulting in decreased negative psychological and academic consequences for students, decreased risk of legal liability for schools, and improved school climate.

In addition to policy content, it is important to consider policy accessibility. The policy content is moot if students are unable to access (and use) the policy. While it is the responsibility of the school to enforce the policy, school faculty and staff cannot be present to address all incidents of sexual harassment. Research has consistently found that harassment occurs 


\begin{tabular}{|c|c|}
\hline Office for Civil Rights (OCR) ${ }^{16 *}$ & American Council on Education ${ }^{17-19}$ \\
\hline $\begin{array}{l}\text { - Issue a policy against sex discrimination } \\
\text { - Publish and adopt grievance procedures } \\
\text { - Incorporate specific plans for investigating and responding to instances } \\
\text { - of sexual harassment } \\
\text { - Designate a prompt time frame for the investigation and complaint process } \\
\text { - Describe where reports can be filed } \\
\text { - Designate at least } 1 \text { person to handle Title IX complaints and inform the } \\
\text { - } \text { - As part of the resolution of sexual harassment incidents, school personnel } \\
\text { need a plan for disciplinary action against harassers } \\
\text { - Ensure that the policy and procedures are accessible to all members } \\
\text { of the school community (eg, students, teachers, parents) }\end{array}$ & $\begin{array}{l}\text { - Create and adopt a definition of sexual harassment } \\
\text { - Publish an explicit policy statement emphasizing intolerance of } \\
\text { - } \text { sexual harassment } \\
\text { - Engalop an accessible grievance procedure for complainants } \\
\text { - Educective communication with those involved in reported } \\
\text { - Educate all members of the school community about the policy } \\
\text { and procedures }\end{array}$ \\
\hline
\end{tabular}

*The first column of this table summarizes key points set forth in the OCR 2001 guidance. Please refer to the original document for a detailed account of the extensive OCR recommendations.

in public spaces with limited adult supervision such as hallways and cafeterias. ${ }^{1,2,6,20}$ Therefore, it is paramount that students have access to the policies put in place to protect them and know how to use the policies on their own behalf. In order to maximize the possibility of policy utilization, students need to have multiple avenues to learn about their rights. The OCR and ACE recognized the importance of policy accessibility by including it as part of their recommendations. Policy accessibility can be increased in numerous ways, such as having handbooks available in the office, resource center, and school library; giving copies to each student every year; and making the policy available on the school Web site.

To date, there are no published evaluations of the degree to which primary and secondary school policies follow federal guidelines regarding content and accessibility. Only 1 study by Moore and Rienzo ${ }^{21}$ examined the compliance of school district sexual harassment policies; however, their study focused on state-level recommendations and guidelines for Florida school district sexual harassment policies rather than on federal-level guidelines.

To further our understanding of sexual harassment policies in K-12 schools, the current study sought to analyze randomly selected policies across 4 Midwestern states regarding 3 key factors: (1) accessibility of policies to students, (2) consistency of policies with federal guidelines regarding content, and (3) consistency of policy content across educational levels (elementary, middle, high school, and districtwide).

First, this study explored the accessibility of sexual harassment policies in an anonymous and youthfriendly venue (ie, the Internet). Approximately 70\% of Americans report having Internet access, ${ }^{22,23}$ and $20 \%$ of all online users are children. ${ }^{24}$ As of July $2005,87 \%$ of 12 - to 17 -year-olds (approximately 21 million teens) reported using the Internet, which rep- resents a $14 \%$ increase in teens' Internet use in 5 years. ${ }^{25}$ Although teens use the Internet for a variety of purposes, research has found that information retrieval on a specific topic is one of the most frequent uses of the Internet for school-aged youth. ${ }^{25-27}$ The Internet is a powerful resource for youth in the United States, particularly for acquiring information. Equally important, the Internet affords a degree of anonymity when making information requests, ${ }^{28}$ thus allowing students to request and acquire information more privately than if attempting to obtain the information in person at school (eg, in the administrative office). Such privacy may increase the likelihood that students will investigate sensitive information, such as sexual harassment policies. Given the nature of students' Internet use and the anonymity it provides, the Internet is an important venue for increasing policy accessibility for today's youth. As such, both the sampling techniques and the analyses used in this study examined sexual harassment policies made available through school Web sites.

Second, this study examined the consistency of sexual harassment policies with federal guidelines regarding content. Specifically, a coding framework consisting of 10 components was developed by the authors based on an in-depth review of the OCR and ACE policy guidelines in order to quantify, systematically, the degree to which the guidelines were consistently applied to school policies, thereby allowing for a standardized comparison of policy completeness across schools.

Finally, this study explored the consistency of policy content across educational/administrative levels including elementary school (ie, kindergarten through 5 th grade), middle school (ie, 6th through 8th grade), high school (ie, 9th through 12th grade), and districtlevel policies (ie, 1 policy applies to all grades and schools throughout the entire school district, with no 
policies at any other educational level). It is important to examine differences across educational levels because harassment research has found that sexual harassment occurs across grade levels, including elementary and middle school., ${ }^{5,2}$ Therefore, policies should accordingly be accessible and equally comprehensive in their content across levels.

With no published literature examining the implementation of the federal guidelines, this study provides insight into the current state of sexual harassment policies. By examining policy accessibility and completeness regarding content across states, we can begin to identify areas for policy improvement.

\section{METHODS}

\section{Sample}

A multistate study design was adopted to examine the extent to which school sexual harassment policies were consistent with federal guidelines. Fifty school districts were randomly selected from each of 4 Midwestern states (Indiana, Michigan, Ohio, and Wisconsin). The US Census School District Demographics System ${ }^{30}$ was used to assess whether the randomly selected set of school districts served populations reflecting the diversity of their respective state (eg, race/ ethnicity, economic status, educational attainment) according to state averages. ${ }^{31}$ In Indiana, Michigan, and Ohio, economically depressed areas and minority populations were underrepresented in our initial sample. To adjust for this, 1 Indiana district was removed from the sample and more economically and racially diverse districts were added to Michigan, Ohio, and Wisconsin. Demographics for the final sample were within $2 \%$ of state averages and included 50 districts from Indiana,
51 districts from Michigan, 51 districts from Ohio, and 50 districts from Wisconsin.

Each district's Web site was examined for the presence or absence of a school policy available online (ie, a general school policy document, not only a sexual harassment policy) at 4 educational levels (elementary school, middle/junior high school, high school, and districtwide). This yielded data for 808 school policies representing all 202 school districts and 4 educational levels. In order to maintain the independence of the data, any school district with both districtwide policies and policies at the other educational levels was excluded from analyses. This resulted in a final sample of 784 general school policies available online representing 196 school districts across all 4 educational levels and evenly distributed across elementary school, middle school, high school, and district levels ( $\mathrm{n}=196$ per level).

\section{Procedure}

First, each online general school policy was coded to establish whether or not it included a sexual harassment policy. All available sexual harassment policies were then coded for the presence or absence of 10 key components derived by the authors from the OCR/ ACE recommendations. Table 2 describes these 10 components in detail. Policies were independently coded by 4 research team members using a 3 phase coding process: (1) pilot coding, (2) independent coding of all 784 policies, and (3) an independent thirdparty reliability check. First, an iterative pilot coding process occurred during which all coders contributed to the development of a comprehensive coding manual that defined each variable with representative examples. This process continued until coding consensus was attained for all variables and all coders

Table 2. Component Names, Meanings, and Examples

\begin{tabular}{|c|c|c|}
\hline Component Name & Component Meaning & Example From Policies \\
\hline Policy against $\mathrm{SH}$ & Is there an explicit policy statement against SH? & SH is against the policy of this middle school. \\
\hline SH definition & Is a definition of SH given? & $\begin{array}{l}\text { SH is any unwanted sexual behavior that interferes with a } \\
\text { student's life. }\end{array}$ \\
\hline SH examples & Are examples of sexually harassing behaviors given? & $\begin{array}{l}\text { Behaviors considered SH include unwanted touching, } \\
\text { sexual-related name-calling, etc. }\end{array}$ \\
\hline School response & $\begin{array}{l}\text { Does the policy state that the school will take action to } \\
\text { stop the harassment? }\end{array}$ & $\begin{array}{l}\text { Administrators will make every effort to stop instances of } \\
\text { SH brought to our attention. }\end{array}$ \\
\hline Grievance procedure & Is a formal grievance procedure identified? & $\begin{array}{l}\text { Any student who has been harassed should complete the } \\
\text { SH report form located in the office. }\end{array}$ \\
\hline Investigation intentions & Does the school indicate that claims will be investigated? & All reports of SH will be investigated. \\
\hline Investigation timeline & $\begin{array}{l}\text { Does the policy indicate a timeline for the investigation } \\
\text { of reports? }\end{array}$ & All reports will be investigated within 6 weeks of the report date. \\
\hline Reporting contact & $\begin{array}{l}\text { Is a person within the school identified as the } \\
\text { SH contact person? }\end{array}$ & $\begin{array}{l}\text { Please speak with the school counselor, who is also the } \\
\text { SH officer, if you have any questions or concerns about SH. }\end{array}$ \\
\hline SH consequences & Are consequences identified for sexual harassers? & $\begin{array}{l}\text { Any student determined to have sexually harassed another } \\
\text { student will receive } 2 \text { detentions. }\end{array}$ \\
\hline Policy education & $\begin{array}{l}\text { Does the policy state how individuals are educated } \\
\text { about SH and the policy? }\end{array}$ & $\begin{array}{l}\text { At the start of each school year, all teachers are required to } \\
\text { read and discuss this policy with their homeroom class. }\end{array}$ \\
\hline
\end{tabular}

$\mathrm{SH}$, sexual harassment. 
reached $90 \%$ agreement. After completing pilot coding, all 784 school policies were independently coded. Thirty percent of the policies were double-coded as an additional check of coder agreement, which ranged from $92.3 \%$ to $94.6 \%$ (average coder agreement was $93.5 \%$ ). Finally, $10 \%$ of the policies were independently coded by the first author (who was not one of the initial 4 coders) and compared to the codes previously obtained. This final reliability check resulted in a $99.1 \%$ rate of agreement.

\section{Measure of Policy Completeness}

In order to evaluate the extent to which the policies addressed the OCR and the ACE guidelines, a summary score was computed using the 10 components derived by the authors from the OCR/ACE recommendations (Table 2). Each component was dichotomously coded (ie, $0=$ component was not present and $\mathrm{l}=$ component was present). The $10 \mathrm{com}$ ponent scores were summed to create an index of policy completeness. This index had a possible range from 0 indicating no components were present to 10 indicating all components were present. Cronbach's alpha was .83, with corrected item-total correlations ranging from .36 to .61 .

\section{RESULTS}

\section{Policy Accessibility}

Of the 784 general school policies in the original sample, only $110(14 \%)$ included sexual harassment policies that were accessible on the Internet (17 elementary school, 33 middle school, 44 high school, and 16 district-level policies). A chi-square difference test was used to determine if significant differences in the sexual harassment policy accessibility existed across educational levels. Significant differences emerged $\left(\chi^{2}=23.05, \mathrm{p}<.05\right.$, Cramer's $\left.V=.17\right)$, and an examination of the standardized residuals revealed that high schools had significantly more sexual harassment policies available online, whereas elementary school and districtwide policies had significantly fewer sexual harassment policies available on the Internet. For all subsequent analyses, nonparametric statistics were used to evaluate the sexual harassment policies that were accessible online $(n=110) .^{32}$

\section{Policy Completeness}

Sexual harassment policies in this sample ranged from 0 to 10 policy components. On average, the policies included fewer than one half (mean $=4.49, \mathrm{SD}=$ $2.97)$ of the 10 components of an effective policy. Table 3 presents the percentage of policies incorporating each component. Factors most likely to be included were consequences for sexual harassment $(66.4 \%)$, sexual harassment definitions $(60.9 \%)$, and
Table 3. Percentage of Policies Including Components of the Policy Completeness Index

\begin{tabular}{lccccc}
\hline Item & $\begin{array}{c}\text { Total } \\
\mathbf{( \% )}\end{array}$ & $\begin{array}{c}\text { Elementary } \\
\mathbf{( \% )}\end{array}$ & $\begin{array}{c}\text { Middle } \\
\mathbf{( \% )}\end{array}$ & $\begin{array}{c}\text { High } \\
\mathbf{( \% )}\end{array}$ & $\begin{array}{c}\text { District } \\
\mathbf{( \% )}\end{array}$ \\
\hline Policy against SH & 56.4 & 23.5 & 81.3 & 54.5 & 61.4 \\
SH definition & 60.9 & 35.3 & 75.0 & 57.6 & 68.2 \\
SH examples & 45.5 & 23.5 & 68.8 & 36.4 & 52.3 \\
School response & 20.0 & 5.9 & 56.3 & 12.1 & 18.2 \\
Grievance procedure & 51.8 & 23.5 & 17.5 & 51.5 & 59.1 \\
Investigation intentions & 38.2 & 23.5 & 56.3 & 33.3 & 40.9 \\
Investigation timeline & 25.5 & 17.6 & 43.8 & 18.2 & 27.3 \\
Reporting contact & 60.6 & 25.0 & 62.5 & 63.6 & 70.5 \\
SH consequences & 66.4 & 41.2 & 81.3 & 60.6 & 75.0 \\
Policy education & 20.0 & 23.5 & 12.1 & 11.4 & 56.3 \\
\hline
\end{tabular}

$\mathrm{SH}$, sexual harassment.

a contact person for sexual harassment reporting $(60.6 \%)$. Conversely, more than one half of all policies did not include the following factors: examples of behaviors constituting sexual harassment (present in $45.5 \%$ ), intentions to investigate allegations of harassment $(38.2 \%)$, a timeline for investigations $(25.5 \%)$, a plan for a school response to stop the behavior $(20.0 \%)$, and a plan to educate the school community about the policy $(20.0 \%)$.

The policy completeness index was used to assess variability in the degree to which online sexual harassment policies $(n=110)$ followed the OCR and ACE guidelines across the 4 educational levels. A Kruskal-Wallis l-way analysis of variance by Ranks test was conducted, revealing significant group-level differences on the policy completeness index $\left(\chi_{\mathrm{k}-\mathrm{w}}^{2}=\right.$ 16.26, $\mathrm{p}<.01)$. Table 4 lists the mean, SD, and range of policy completeness scores across educational levels. Two post hoc analyses were conducted, the MannWhitney followed by the Holm's Step-Down procedure to adjust for type I error resulting from multiple comparisons. ${ }^{32}$ After correcting for type I error, both districtand high school-level policies were found to have significantly more critical components than elementary school-level policies $(\mathrm{p}<.01$; see Table 5$)$. However, all other comparisons across educational levels were nonsignificant.

It is worth noting that prior to adjusting for type I error, all but 3 comparisons were significant. Specifically, district policies included significantly more critical components compared to middle $(\mathrm{p}<.05)$ and

Table 4. Mean, SD, and Range of Scores on the Policy Completeness Index Across Educational Levels

\begin{tabular}{lcccc}
\hline Educational Level & N & Mean & SD & Range \\
\hline Elementary & 17 & 2.41 & 2.76 & $0-10$ \\
Middle & 33 & 4.00 & 2.51 & $0-9$ \\
High & 44 & 4.84 & 2.76 & $0-10$ \\
District & 16 & 6.44 & 3.42 & $1-10$ \\
All levels & 110 & 4.45 & 2.99 & $0-10$ \\
\hline
\end{tabular}


Table 5. Holm's Step-Down Procedure for Post Hoc Comparisons of Educational Levels on Critical Components

\begin{tabular}{lllcc}
\hline I & Group & \multicolumn{1}{c}{ Comparison } & $\begin{array}{c}\text { Obtained } \\
\text { p Value }\end{array}$ & \multicolumn{1}{c}{$\boldsymbol{\alpha / ( k - \mathbf { i } + \mathbf { 1 } )}$} \\
\hline 1 & 1 vs 2 & District vs elementary & .002 & $.05 /(6-1+1)=.0083$ \\
2 & 2 vs 4 & Elementary vs high & .002 & $.05 /(6-2+1)=.01$ \\
3 & 1 vs 3 & District vs middle & .015 & $.05 /(6-3+1)=.0125$ \\
4 & 2 vs 3 & Elementary vs middle & .018 & $.05 /(6-4+1)=.0167$ \\
5 & 1 vs 4 & District vs high & .071 & $.05 /(6-5+1)=.025$ \\
6 & 3 vs 4 & Middle vs high & .190 & $.05 /(6-6+1)=.05$ \\
\hline
\end{tabular}

elementary school policies $(\mathrm{p}<.01)$. Both high and middle school policies included significantly more critical components than the elementary school policies $(p<.01$ and $p<.05$, respectively). With a larger sample size and more power, these significant effects may remain after adjusting for type I error.

When examining which components were included in policies, significant differences were found across educational levels. Chi-square difference tests revealed significant differences in the presence of a policy statement against sexual harassment, sexual harassment examples, school response, reporting contact, sexual harassment consequences, and policy education (Table 6). Nonsignificant trends across educational levels were found for defining sexual harassment and identifying the grievance procedures. Examination of the standardized residuals for the chi-square tests revealed that the significant differences lie with the district and elementary school policies. Specifically, sexual harassment examples, school response, and sexual harassment policy education were included significantly more often in district-level policies compared to all other levels. Conversely, elementary school policies included the following components significantly less often compared to other education levels: policy statements against sexual harassment, sexual harassment definitions, sexual harassment examples, grievance procedures, reporting contact person, and sexual harassment consequences. Overall, more components

Table 6. Chi-Square and Cramer's V Differences Across Educational Level on Critical Components

\begin{tabular}{lcc}
\hline & $\chi^{\mathbf{2}}$ & Cramer's $\boldsymbol{V}$ \\
\hline Policy against SH & $11.97^{*}$ & .33 \\
SH definition & $7.15^{+}$ & .26 \\
SH examples & $8.72^{*}$ & .28 \\
School response & $16.63^{*}$ & .39 \\
Grievance procedure & $7.11^{\dagger}$ & .25 \\
Investigation intentions & 4.23 & .20 \\
Investigation timeline & 4.37 & .20 \\
Reporting contact & $10.43^{*}$ & .31 \\
SH consequences & $8.38^{*}$ & .28 \\
Policy education & $16.60^{*}$ & .39 \\
\hline
\end{tabular}

$\mathrm{SH}$, sexual harassment.

${ }^{*} p<.05 ;{ }^{\dagger} p<.10$ (trend). were missing from the elementary school policies than were present.

\section{DISCUSSION}

Sexual harassment in primary and secondary schools has only recently been recognized as a serious concern for students and schools. Research has linked sexual harassment with poor psychological health and academic withdrawal. ${ }^{1,2,6,7}$ School policies regarding sexual harassment have been identified as essential to the reduction of sexual harassment among students. ${ }^{16-19}$ However, little is known about sexual harassment policies in K-12 schools. The OCR guidelines for the construction of nondiscrimination policies and procedures that meet Title IX regulations and the ACE recommendations offer a good starting place for evaluating sexual harassment policies. To the authors' knowledge, this study is the first to examine school policies across multiple states with regard to their accessibility to youth and the comprehensiveness of their content. These findings demonstrate that there is vast inconsistency across schools regarding their availability of sexual harassment policies online.

When exploring policy accessibility, we found that less than $15 \%$ of schools make their sexual harassment policies available online, despite the fact that they have established means of providing information via the Web, as evidenced by the fact that all the 196 districts analyzed had their general school policies available on the school Web sites. In both the OCR and the ACE guidelines, accessibility is a critical component to sexual harassment policy implementation. Given the extensive use of the Internet by information-seeking youth and the anonymity it provides, schools are failing to use an important venue for communicating sexual harassment policy information to students. Increased accessibility may promote policy awareness and utilization, and students may be more likely to report sexual harassment as the reporting process is demystified. Additionally, public knowledge of the process promotes accountability within the system because students are aware of what should be happening and can advocate for themselves if protocol is not followed. Based on this sample of school policies, accessibility is an area for significant policy improvement.

Of policies accessible online, there were vast inconsistencies in the incorporation of the components specified in the OCR/ACE guidelines. The components most consistently included were, at best, present in slightly more than $60 \%$ of the policies. Some components were missing in as many as $80 \%$ of the policies. For example, some policies identify consequences for sexual harassing behaviors without defining it. Additionally, policies rarely included a plan for educating the school community; thus, schools may not be educating students about their right to a harassment-free 
educational environment or the consequences of sexually harassing behaviors. All 10 of the examined components are essential to a comprehensive policy; missing any 1 limits the potential utility and effectiveness of the policy. Furthermore, according to the OCR, by failing to incorporate components specified as part of an effective policy, ${ }^{16-19}$ schools may be exposing themselves to an increased risk of liability for failing to properly address sexual harassment under Title IX (eg, by failing to communicate intolerance for sexual harassment or adopt proper procedures for responding to incidents when they arise).

In evaluating differences across educational levels, policies at the elementary school level were consistently found to be relatively inaccessible and those that were accessible lacked comprehensive coverage of the OCR/ACE guidelines. This may reflect a belief that sexual harassment is not a concern among elementary school students and, therefore, not a priority. This belief may be attributed to the tendency for adults to presume that elementary school children are incapable of sex-related behaviors, particularly sexual harassment. Nevertheless, research has documented that sexual harassment indeed occurs among elementary school children. ${ }^{1,2,5,6,33}$ In fact, the American Association of University Women's studies found that approximately one third of their sample of 2064 public school students recalled first experiencing harassment prior to the sixth grade. ${ }^{1,2}$ Furthermore, Murnen and Smolak's ${ }^{5}$ study was based entirely on elementary school children, the majority of whom had already experienced sexual harassment. In addition to the research-based evidence that sexual harassment emerges in primary school, several sexual harassment court cases have been brought forward involving elementary school-aged youth (eg, Davis v Monroe County School District and Fitzgerald v Barnstable School Committee).

Given the repeated findings that sexual harassment occurs among elementary school students, it is all the more critical that elementary school policies be comprehensive and accessible to students and their parents. Additionally, by not addressing sexual harassment at this early stage of students' academic lives, schools send the message that sexual harassment is either not a problem or not a priority. ${ }^{16}$ Although the effects may not be immediate, it may increase the likelihood that, in the future, students could perceive harassing behaviors as acceptable, there is no recourse when harassment occurs, or both.

It is important to note some limitations to the findings presented here. First, this study addresses whether schools have their sexual harassment policies available in a youth-friendly, easily accessible, and anonymous location (ie, the Internet). It is possible that schools without policies accessible online do indeed have sexual harassment policies available elsewhere. Second, we did not assess the accessibility of the policies from restricted computers. It is possible that filters intended to protect youth from adult content used by schools and public libraries may prohibit students from accessing sexual harassment information (ie, because of the search term "sexual"). This is an important consideration when institutions set their parameters for censoring the Internet. Third, we did not evaluate the ease of finding the sexual harassment policy on the school Web site. While our team successfully navigated the school Web sites, it is important for schools to consider the organization and searchability of their sites. Fourth, this study did not assess the quality of policy content. While we determined, for example, whether a policy had a definition of sexual harassment, we did not evaluate whether the definition was understandable or comprehensive. Finally, the appropriateness of policy language is an important factor that we did not examine. If the language is not child-friendly and written at the appropriate reading level, or if policies are not available in the primary languages spoken by the children and their parents, then their availability on the Internet is irrelevant.

Despite these limitations, this study highlights the need for greater accessibility and consistency of sexual harassment policies across educational levels. Particular attention is needed at the elementary school level. Both the frequency and the negative impact of sexual harassment on students and schools make further analysis of sexual harassment policy implementation necessary. Future research should analyze the quality of policy content both for the policy overall and for each critical component. Furthermore, regardless of the presence of the critical components, a policy is beneficial only in so far as it is effectively implemented. One specific area warranting research is the link between sexual harassment policies and procedures and bullying prevention initiatives. Do the bullying prevention initiatives draw relevant links between gender-based bullying behaviors, sexual harassment, and Title IX, directing students and staff to the school's sexual harassment policies and procedures? Existing research suggests the need for improved training regarding the treatment of gender-based bullying incidents. ${ }^{34}$ Additional research is needed regarding appropriate school responses to sexual harassment across educational levels; policy understanding and utilization by faculty, staff, and students; and consistency of policy enforcement.

\section{REFERENCES}

1. American Association of University Women. Hostile Hallways: The AAUW Survey on Sexual Harassment in American Schools. Washington, DC: American Association of University Women Educational Foundation; 1993.

2. American Association of University Women. Hostile Hallways: Bullying, Teasing, and Sexual Harassment in School. Washington, 
DC: American Association of University Women Educational Foundation; 2001.

3. Stein N. Classrooms and Courtrooms: Facing Sexual Harassment in K-12 Schools. New York, NY: Teacher's College Press, Columbia University; 1999.

4. Fineran S, Bennett L. Gender and power issues of peer sexual harassment among teenagers. J Interpers Violence. 1999;14(6):626-641.

5. Murnen SK, Smolak L. The experience of sexual harassment among grade-school students: early socialization of female subordination? Sex Roles. 2000;43(1/2):1-17.

6. Trigg M, Wittenstrom $K$. That's the way the world really goes: sexual harassment and New Jersey teenagers. Initiatives. 1996;57(2):55-65.

7. Shakeshaft C, Mandel L, Johnson YM. Boys call me cow. Educ Leadersh. 1997;55(October):22-25.

8. Freiberg HJ, Stein TA. Measuring, improving, and sustaining learning environments. In: Freiberg HJ, ed. School Climate: Measuring, Improving, and Sustaining Healthy Learning Environments. Philadelphia, Pa: Falmer; 1999: 11-29.

9. Moos RH. Evaluating Educational Environments: Procedures, Measures, Findings, and Policy Implications. San Francisco, Calif: Jossey-Bass; 1979.

10. Tirozzi G, Uro G. Education reform in the United States: national policy in support for school improvement. Am Psychol. 1997;52: 241-249.

11. Cherner-Ranft ME. The empty promise of Title IX: why girls need courts to reconsider liability standards and preemption in school sexual harassment cases. Northwest Univ Law Rev. 2003;97(4): 1891-1926.

12. Kopels S, Dupper DR. School-based peer sexual harassment. Child Welfare. 1999;78(4):435-460.

13. Romano P. Davis v. Monroe County Board of Education: Title IX recipients' "head in the sand" approach to peer sexual harassment may incur liability. $J$ Law Educ. 2001;30(1):63-84.

14. Yaffe E. Expensive, illegal, and wrong: sexual harassment in our schools. Phi Delta Kappan. 1995;77(3):1-15.

15. Mann JA, Miller FW. Title IX: a student's right to a harassmentfree education. J Cases Educ Leadersh. 2000;3(2):1-7.

16. Office for Civil Rights, US Department of Education. Revised sexual harassment guidance: harassment of students by school employees, other students, and third parties. 2001. Available at: http://www.ed.gov/about/offices/list/ocr/docs/shguide.pdf. Accessed February 23, 2005.

17. Dozier J. Sexual harassment: it can happen here. AGB Reports. 1990;32(1):15-20.

18. Holub J. Addressing Sexual Harassment on Campus. Los Angeles, Calif: ERIC Clearinghouse for Community Colleges; 1996. Report no. EDO-JC-96-09.

19. Wagner K. Prevention and intervention: developing campus policies and procedures. Initiatives. 1990;52(4):37-45.
20. Lichty LF, Torres JMC, Tatebe D, et al. A qualitative exploration of youth sexual harassment. Paper presented at: International Coalition Against Sexual Harassment Conference; August 14-15, 2005; Philadelphia, Pa.

21. Moore MJ, Rienzo BA. Sexual harassment policies in Florida school districts. J Sch Health. 1998;68(6):237-242.

22. Internet World Stats. Internet usage statistics for the Americas: internet user statistics and populations stats for 51 countries and regions-North America, Central America, South America, and the Caribbean. 2005. Available at: http://www.internetworldstats. com/stats2.htm. Accessed July 12, 2005.

23. Nielsen/NetRatings. Three out of four Americans have access to the internet according to Nielsen/Netratings: online population surges past 200 million mark for the first time. 2004. Available at: www.nielsen-netratings.com $\backslash p r \backslash p r \_040318$.pdf. Accessed July 12,2005

24. Nielsen/NetRatings. Kids account for one out of five internet surfers in the U.S.; more than 27 million American kids connect online, according to Nielsen//Netratings. 2003. Available at: http:// www.nielsen-netratings.com./pr/pr_031021_us.pdf. Accessed July 12, 2005.

25. Lenhart A, Madden M, Hitlin P. Teens and technology: youth are leading the transition to a fully wired and mobile nation. 2005. Available at: http://www.pewinternet.org/pdfs/PIP_Teens_ Tech_July2005web.pdf. Accessed August 13, 2005.

26. Kafai YB, Sutton S. Elementary school students' computer and internet use at home: current trends and issues. J Educ Comput Res. 1999;21(3):345-362.

27. Valkenburg PM, Soeters KE. Children's positive and negative experiences with the internet: an exploratory study. Commun Res. 2001;28(5):652-675.

28. Johnson D. Anonymity and the internet. Futurist. 2000;34(4):12.

29. Lacasse A, Purdy KT, Mendelson MJ. The mixed company they keep: potentially offensive sexual behaviors among adolescents. Int J Behav Dev. 2003;27(6):532-540.

30. National Center for Education Statistics. U.S. Census School District Demographics System. 2000. Available at: http://nces.ed. gov/surveys/sdds/main l.asp. Accessed April 5, 2004.

31. US Census Bureau. State and county QuickFacts. 2000. Available at: http://quickfacts.census.gov/qfd/index.html. Accessed November 20, 2004.

32. Pett M. Nonparametric Statistics for Health Care Research: Statistics for Small Samples and Unusual Distributions. Thousand Oaks, Calif: Sage Publications; 1997.

33. Stein N. From the margins to the mainstream: sexual harassment in K-12 schools. Initiatives. 1996;57(3):19-26.

34. Anagnostopoulos D, Buchanan NT, Pereira C, Lichty LF. School staff responses to gender-based bullying as moral interpretation: an exploratory study. Educ Policy. In press. 